\title{
EFFECT OF INTERMEDIATE SUPPORTS LOCATION ON NATURAL FREQUENCIES OF MULTIPLE CRACKED CONTINUOUS BEAMS
}

\author{
Do Nam ${ }^{1}$, Nguyen Tien Khiem ${ }^{1,2, *}$, Le Khanh Toan ${ }^{2}$, \\ Nguyen Thi Thao ${ }^{2}$, Pham Thi Ba Lien ${ }^{3}$ \\ ${ }^{1}$ VNU University of Engineering and Technology, Hanoi, Vietnam \\ ${ }^{2}$ Institute of Mechanics, Vietnam Academy of Science and Technology, Hanoi, Vietnam \\ ${ }^{3}$ University of Transport and Communication, Vietnam \\ *E-mail: ntkhiem@imech.vast.vn \\ Received November 09, 2017
}

\begin{abstract}
The present paper deals with free vibration of multiple cracked continuous beams with intermediate rigid supports. A simplified method is proposed to obtain general solution of free vibration in cracked beam with intermediate supports that is then used for natural frequency analysis of the beam in dependence upon cracks and support locations. Numerical results show that the support location or ratio of span lengths in combination with cracks makes a significant effect on eigenfrequency spectrum of beam. The discovered effects of support locations on eigenfrequency spectrum of cracked continuous beam are useful for detecting not only cracks but also positions of vanishing deflection on the beam.
\end{abstract}

Keywords: Continuous beam, multi-span beam, multiple cracked beam, natural frequency.

\section{INTRODUCTION}

Multispan or continuous beams are an important model of structures in the bridge and mechanical engineering. Dynamic analysis of such the structures is essential but difficult problem that was studied for long time ago. One of the key questions in dynamics of the continuous beam is determining its natural frequencies and mode shapes that provide an appropriate tool to solve the forced vibration problem of the structures. The free vibration problem of continuous beam was first investigated as a beam with elastic supports [1,2] that could be an approximate model of beam with rigid supports as the stiffness of the elastic supports is very large. The problem of free vibration of actual beam with intermediate rigid supports was solved by using the Rayleigh-Ritz method [3] with trial functions being a solution of the beam under static load. Saeedi and Bhat [4] proposed to study free vibration of beam with rigid supports by solving the forced vibration problem of beam without supports under loads concentrated at the supports. Zheng et

(C) 2018 Vietnam Academy of Science and Technology 
al. [5] determined mode shapes of multispan beam by the mode shape of beam without supports combined with cubic spline functions which are chosen from the zero deflection condition at the supports and boundary conditions. These mode shapes have been then used to study response of the multispan beam to moving load. Ichikawa et al. [6] have constructed exact expression for mode shapes and employed for dynamic analysis of simply supported multispan beam subjected to moving mass. While the aforementioned studies deal with Euler-Bernoulli beam model, some problems of free and forced vibration of multispan Timoshenko beam carrying a number of spring-mass systems were investigated by Yesilce el al. $[7,8]$. The dynamic stiffness method was developed by Henchi et al. [9] for free vibration of multispan beam and the so-called spectral element method has been used by Azizi et al. [10] for analysis of response of multispan beam subjected to moving load. Though dynamics of intact multispan beams has been intensively studied as shown above for instance, there is very few published papers on vibration of multispan beams with cracks. This is probably because of that presence of cracks in a beam makes the problem of vibration more complicate, especially in the case of beam with intermediate supports. Nevertheless, first attempts have been recently accomplished in [11-14] by using the conventional method to compute natural frequencies and mode shapes of cracked multispan beams. Namely, Liu et al. [11] and Lien and Hao [12] have demonstrated that change in mode shapes of multispan beam due to cracks could be numerically examined and Sharma et al. $[13,14]$ have shown that natural frequencies are promising to use for crack detection in the multispan beams. Recently, Tan et al. [15] studied both the forward and inverse problems for multispan continuous beam with arbitrary number of cracks and spring-mass systems. However, a shortcoming of the studies is the need to assemble either transfer or stiffness matrix over not only beam steps but also the crack locations so that equations established for computing natural frequencies and mode shapes are very complicated. This paper aimed to simplify the transfer matrix method applied for multispan beam with arbitrary number of cracks by using shape function found as general solution of free vibration in a single span beam containing an arbitrary number of cracks. The latter solution has been first obtained by the first author in [16] based on the closed-form solution for vibration modes of beam with multiple open cracks proposed in [17]. Moreover, the simplified method and obtained frequency equation allow more comprehensive investigation of natural frequencies in dependence on multiple cracks and locations of intermediate supports in the multispan beams with different boundary conditions. The revealed herein effects of support locations on eigenfrequency spectrum of cracked continuous beam are useful guidelines for detecting not only cracks but also positions of vanishing deflection on the beam.

\section{THEORETICAL METHODOLOGY}

Let's consider a continuous Euler-Bernoulli beam of length $L$, cross section area $A=$ $b \times h$ and moment of inertia $I=b h^{3} / 12$ that is rigidly supported at positions

$$
0<x_{1}<x_{2}<\ldots<x_{n}<L,
$$

where the beam's transverse displacement vanishes

$$
\phi\left(x_{j}\right)=0, j=1,2, \ldots, n \text {. }
$$


Obviously, the intermediate rigid supports divide the beam into $n+1$ spans $\left(x_{j-1}, x_{j}\right)$, $j=1, \ldots, n+1$ and free vibration of the beam in every span is described by the equation

$$
\frac{d^{4} \phi(x)}{d x^{4}}+\lambda^{4} \phi(x)=0, \lambda^{4}=\omega^{2} \rho A / E I .
$$

Boundary conditions for the beam are assumed in general form

$$
\phi^{\left(p_{0}\right)}(0)=\phi^{\left(q_{0}\right)}(0)=\phi^{\left(p_{1}\right)}(L)=\phi^{\left(q_{1}\right)}(L)=0,
$$

with the integers $p_{0}, q_{0}, p_{1}, q_{1}$ denoting derivative's orders of a function and could be equal to one of the values $0,1,2,3$ in dependence on specific boundary conditions.

Suppose, furthermore, that the span $S_{j}=\left(x_{j-1}, x_{j}\right)$ has been cracked at positions $e_{j k}$ with corresponding depths $a_{j k}, k=1, \ldots, n_{j}$. So that the compatibility conditions at the cracks are

$$
\begin{aligned}
& \phi\left(e_{j k}+0\right)=\phi\left(e_{j k}-0\right), \quad \phi^{\prime \prime}\left(e_{j k}+0\right)=\phi^{\prime \prime}\left(e_{j k}-0\right), \quad \phi^{\prime \prime \prime}\left(e_{j k}+0\right)=\phi^{\prime \prime \prime}\left(e_{j k}-0\right), \\
& {\left[\phi^{\prime}\left(e_{j k}+0\right)-\phi^{\prime}\left(e_{j k}-0\right)\right]=\gamma_{j k} \phi^{\prime \prime}\left(e_{j k}\right), \quad \gamma_{j k}=E I \theta\left(a_{j k}\right), \quad k=1, \ldots, n_{j},}
\end{aligned}
$$

where $\gamma_{j k}$ is so-called crack magnitude and $\theta(a)$ is a function of crack depth defined accordingly to the fracture mechanics theory of crack [18].

As well known in the vibration theory that general solution of Eq. (2) in span $\left(x_{j-1}, x_{j}\right)$ denoted by $\phi_{j}(x, \lambda)$ is expressed in the form

$$
\phi_{j}(x, \lambda)=A_{j} L_{j 1}(\lambda x)+B_{j} L_{j 2}(\lambda x)+C_{j} L_{j 3}(\lambda x)+D_{j} L_{j 4}(\lambda x),
$$

with $A_{j}, B_{j}, C_{j}, D_{j}$ being constants and functions $L_{j r}(\lambda x), r=1,2,3,4$ are particular solutions of the equation inside the beam segment that would be constructed below. Applying the conditions (1) for solution (5) in the beam span $\left(x_{j-1}, x_{j}\right), j=2, \ldots, n$ one obtains

$$
\begin{aligned}
& A_{j} L_{1 j}\left(\lambda x_{j-1}\right)+B_{j} L_{2 j}\left(\lambda x_{j-1}\right)+C_{j} L_{3 j}\left(\lambda x_{j-1}\right)+D_{j} L_{4 j}\left(\lambda x_{j-1}\right)=0, \\
& A_{j} L_{1 j}\left(\lambda x_{j}\right)+B_{j} L_{2 j}\left(\lambda x_{j}\right)+C_{j} L_{3 j}\left(\lambda x_{j}\right)+D_{j} L_{4 j}\left(\lambda x_{j}\right)=0,
\end{aligned}
$$

that allow eliminating two from the constants $A_{j}, B_{j}, C_{j}, D_{j}$ as

$$
A_{j}=\alpha_{11}(j) C_{j}+\alpha_{21}(j) D_{j}, \quad B_{j}=\alpha_{12}(j) C_{j}+\alpha_{22}(j) D_{j},
$$

where

$$
\begin{aligned}
& \alpha_{11}(j)=\left[L_{2 j}\left(\lambda x_{j-1}\right) L_{3 j}\left(\lambda x_{j}\right)-L_{2 j}\left(\lambda x_{j}\right) L_{3 j}\left(\lambda x_{j-1}\right)\right] / d_{j}, \\
& \alpha_{12}(j)=\left[L_{2 j}\left(\lambda x_{j-1}\right) L_{4 j}\left(\lambda x_{j}\right)-L_{2 j}\left(\lambda x_{j}\right) L_{4 j}\left(\lambda x_{j-1}\right)\right] / d_{j}, \\
& \alpha_{21}(j)=\left[L_{1 j}\left(\lambda x_{j}\right) L_{3 j}\left(\lambda x_{j-1}\right)-L_{1 j}\left(\lambda x_{j-1}\right) L_{3 j}\left(\lambda x_{j}\right)\right] / d_{j}, \\
& \alpha_{22}(j)=\left[L_{1 j}\left(\lambda x_{j}\right) L_{4 j}\left(\lambda x_{j-1}\right)-L_{4 j}\left(\lambda x_{j}\right) L_{1 j}\left(\lambda x_{j-1}\right)\right] / d_{j}, \\
& d_{j}=L_{1 j}\left(\lambda x_{j-1}\right) L_{2 j}\left(\lambda x_{j}\right)-L_{1 j}\left(\lambda x_{j}\right) L_{2 j}\left(\lambda x_{j-1}\right) .
\end{aligned}
$$

Substituting (6) into (5) leads the expression (5) of solution $\phi_{j}(x, \lambda)$ to be simplified as

where

$$
\phi_{j}(x, \lambda)=C_{j} \widehat{L}_{1 j}(\lambda x)+D_{j} \widehat{L}_{2 j}(\lambda x), \quad j=2, \ldots, n,
$$

$$
\begin{aligned}
& \widehat{L}_{j 1}(x)=L_{j 3}(x)+\alpha_{11}(j) L_{j 1}(x)+\alpha_{21}(j) L_{j 2}(x), \\
& \widehat{L}_{2 j}(x)=L_{j 4}(x)+\alpha_{11}(j) L_{j 1}(x)+\alpha_{21}(j) L_{j 2}(x) .
\end{aligned}
$$


Particularly, for the first and last spans that are enclosed respectively by $\left(0, x_{1}\right)$ and $\left(x_{n}, L\right)$, the conditions

$$
\phi_{1}^{\left(q_{0}\right)}(0)=\phi_{1}\left(x_{1}\right)=\phi_{n+1}\left(x_{n}\right)=\phi_{n+1}^{\left(q_{1}\right)}(L)=0,
$$

must be satisfied or

$$
\begin{aligned}
& A_{1} L_{11}^{\left(q_{0}\right)}(0)+B_{1} L_{12}^{\left(q_{0}\right)}(0)+C_{1} L_{13}^{\left(q_{0}\right)}(0)+D_{1} L_{14}^{\left(q_{0}\right)}(0)=0, \\
& A_{1} L_{11}\left(\lambda x_{1}\right)+B_{1} L_{12}\left(\lambda x_{1}\right)+C_{1} L_{13}\left(\lambda x_{1}\right)+D_{1} L_{14}\left(\lambda x_{1}\right)=0, \\
& A_{n+1} L_{n+1,1}^{\left(q_{1}\right)}(\lambda L)+B_{n+1} L_{n+1,2}^{\left(q_{1}\right)}(\lambda L)+C_{n+1} L_{n+1,3}^{\left(q_{1}\right)}(\lambda L)+D_{n+1} L_{n+1,4}^{\left(q_{1}\right)}(\lambda L)=0, \\
& A_{n+1} L_{n+1,1}\left(\lambda x_{n}\right)+B_{n+1} L_{n+1,2}\left(\lambda x_{n}\right)+C_{n+1} L_{n+1,3}\left(\lambda x_{n}\right)+D_{n+1} L_{n+1,4}\left(\lambda x_{n}\right)=0 .
\end{aligned}
$$

The latter equations enable to extend the expression (7) for the first $(j=1)$ and last $(n+1)$ spans with

$$
\begin{aligned}
& \alpha_{11}(1)=\left[L_{21}^{\left(q_{0}\right)}\left(\lambda x_{0}\right) L_{31}\left(\lambda x_{1}\right)-L_{21}\left(\lambda x_{1}\right) L_{31}^{\left(q_{0}\right)}\left(\lambda x_{0}\right)\right] / d_{1}, \\
& \alpha_{12}(1)=\left[L_{21}^{\left(q_{0}\right)}\left(\lambda x_{0}\right) L_{41}\left(\lambda x_{1}\right)-L_{21}\left(\lambda x_{1}\right) L_{41}^{\left(q_{0}\right)}\left(\lambda x_{0}\right)\right] / d_{1}, \\
& \alpha_{21}(1)=\left[L_{11}\left(\lambda x_{1}\right) L_{31}^{\left(q_{0}\right)}\left(\lambda x_{0}\right)-L_{31}\left(\lambda x_{1}\right) L_{11}^{\left(q_{0}\right)}\left(\lambda x_{0}\right)\right] / d_{1}, \\
& \alpha_{22}(1)=\left[L_{11}\left(\lambda x_{1}\right) L_{41}^{\left(q_{0}\right)}\left(\lambda x_{0}\right)-L_{11}^{\left(q_{0}\right)}\left(\lambda x_{0}\right) L_{41}\left(\lambda x_{1}\right)\right] / d_{1}, \\
& \alpha_{11}(n+1)=\frac{L_{2, n+1}\left(\lambda x_{n}\right) L_{3, n+1}^{\left(q_{1}\right)}(\lambda L)-L_{2, n+1}^{\left(q_{1}\right)}(\lambda L) L_{3, n+1}\left(\lambda x_{n}\right)}{d_{n+1}}, \\
& \alpha_{12}(n+1)=\frac{L_{2, n+1}\left(\lambda x_{n}\right) L_{4, n+1}^{\left(q_{1}\right)}(\lambda L)-L_{2, n+1}^{\left(q_{1}\right)}(\lambda L) L_{4, n+1}\left(\lambda x_{n}\right)}{d_{n+1}}, \\
& \alpha_{21}(n+1)=\frac{L_{1, n+1}^{\left(q_{1}\right)}(\lambda L) L_{3, n+1}\left(\lambda x_{n}\right)-L_{3, n+1}^{\left(q_{1}\right)}(\lambda L) L_{1, n+1}\left(\lambda x_{n}\right)}{d_{n+1}}, \\
& \alpha_{22}(n+1)=\frac{L_{1, n+1}^{\left(q_{1}\right)}(\lambda L) L_{4, n+1}\left(\lambda x_{n}\right)-L_{1, n+1}\left(\lambda x_{n}\right) L_{4, n+1}^{\left(q_{1}\right)}(\lambda L)}{d_{n+1}}, \\
& d_{1}=L_{11}^{\left(q_{0}\right)}\left(\lambda x_{0}\right) L_{12}\left(\lambda x_{1}\right)-L_{12}^{\left(q_{0}\right)}\left(\lambda x_{0}\right) L_{11}\left(\lambda x_{1}\right), \\
& d_{n+1}=L_{n+1,2}^{\left(q_{1}\right)}(\lambda L) L_{n+1,1}\left(\lambda x_{n}\right)-L_{n+1,1}^{\left(q_{1}\right)}(\lambda L) L_{n+1,2}\left(\lambda x_{n}\right) .
\end{aligned}
$$

Thus, expressions (7)-(8) are now valid for all $j=1,2, \ldots, n+1$.

Now, satisfying the continuity conditions at the intermediate supports

$$
\phi_{j}^{\prime}\left(x_{j}, \lambda\right)=\phi_{j+1}^{\prime}\left(x_{j}, \lambda\right), \quad \phi_{j}^{\prime \prime}\left(x_{j}, \lambda\right)=\phi_{j+1}^{\prime \prime}\left(x_{j}, \lambda\right), \quad j=1, \ldots, n,
$$

by solution (7) leads to

$$
\left\{C_{j+1}, D_{j+1}\right\}^{T}=[\mathbf{T}(j+1, j)] \cdot\left\{C_{j}, D_{j}\right\}^{T},
$$

where

$$
[\mathbf{T}(j+1, j)]=\left[\begin{array}{cc}
\widehat{L}_{j+1,1}^{\prime}\left(\lambda x_{j}\right) & \widehat{L}_{j+1,2}^{\prime}\left(\lambda x_{j}\right) \\
\widehat{L}_{j+1,1}^{\prime \prime}\left(\lambda x_{j}\right) & \widehat{L}_{j+1,2}^{\prime \prime}\left(\lambda x_{j}\right)
\end{array}\right]^{-1} \times\left[\begin{array}{cc}
\widehat{L}_{j 1}^{\prime}\left(\lambda x_{j}\right) & \widehat{L}_{j 2}^{\prime}\left(\lambda x_{j}\right) \\
\widehat{L}_{j 1}^{\prime \prime}\left(\lambda x_{j}\right) & \widehat{L}_{j 2}^{\prime \prime}\left(\lambda x_{j}\right)
\end{array}\right] .
$$

The recurrent relationship (10) allows us to obtain

$$
\left\{C_{j}, D_{j}\right\}^{T}=\left[\mathbf{H}_{j}\right]\left\{C_{1}, D_{1}\right\}^{T}, \quad j=2, \ldots, n+1,
$$




$$
\left[\mathbf{H}_{j}\right]=[\mathbf{T}(j, j-1)] \cdot \ldots \cdot[\mathbf{T}(2,1)]=\left[\begin{array}{ll}
H_{11}(j) & H_{12}(j) \\
H_{21}(j) & H_{22}(j)
\end{array}\right],
$$

that enables to rewrite the solution (7) in the form

$$
\begin{gathered}
\phi_{j}(x, \lambda)=C_{1} G_{1 j}(\lambda x)+D_{1} G_{2 j}(\lambda x), \quad j=2, \ldots, n, \\
G_{1 j}(x)=H_{11}(j) \widehat{L}_{1 j}(x)+H_{21}(j) \widehat{L}_{2 j}(x), \quad G_{2 j}(x)=H_{12}(j) \widehat{L}_{1 j}(x)+H_{22}(j) \widehat{L}_{2 j}(x) .
\end{gathered}
$$

In particular,

$$
\phi_{1}(x, \lambda)=C_{1} \widehat{L}_{11}(\lambda x)+D_{1} \widehat{L}_{12}(\lambda x), \quad \phi_{n+1}(x, \lambda)=C_{1} G_{n+1,1}(\lambda x)+D_{1} G_{n+1,2}(\lambda x),
$$

where

$$
\begin{aligned}
& G_{n+1,1}(x)=H_{11}(n+1) \widehat{L}_{n+1,1}(x)+H_{21}(n+1) \widehat{L}_{n+1,2}(x), \\
& G_{n+1,2}(x)=H_{12}(n+1) \widehat{L}_{n+1,1}(x)+H_{22}(n+1) \widehat{L}_{n+1,2}(x) .
\end{aligned}
$$
yields

Applying the unused boundary conditions $\phi_{1}^{\left(p_{0}\right)}(0)=\phi_{n+1}^{\left(p_{1}\right)}(L)=0$ for functions (16)

$$
C_{1} \widehat{L}_{11}^{\left(p_{0}\right)}(0)+D_{1} \widehat{L}_{12}^{\left(p_{0}\right)}(0)=0, \quad C_{1} G_{n+1,1}^{\left(p_{1}\right)}(\lambda x)+D_{1} G_{n+1,2}^{\left(p_{1}\right)}(\lambda x)=0 .
$$

For existence of non-trivial solution of equations (17) with respect to constants $C_{1}, D_{1}$ it must be satisfied the condition

$$
D(\lambda) \equiv G_{n+1,2}^{\left(p_{1}\right)}(\lambda L) \widehat{L}_{11}^{\left(p_{0}\right)}(0)-G_{n+1,1}^{\left(p_{1}\right)}(\lambda L) \widehat{L}_{12}^{\left(p_{0}\right)}(0)=0,
$$

that is usually acknowledged as frequency equation for multispan beam. Roots of the equation $\lambda_{1}, \lambda_{2}, \lambda_{3}, \ldots$ called eigenvalue or frequency parameter allow the natural frequencies of multispan beam to be calculated as

$$
\omega_{k}=\lambda_{k}^{2} \sqrt{E I / \rho A}, \quad k=1,2,3, \ldots
$$

For every natural frequency (19), corresponding mode shape is

$$
\phi_{j k}\left(x, \lambda_{k}\right)=\bar{C}_{j}\left[\widehat{L}_{11}^{\prime \prime}(0) G_{2 j}\left(\lambda_{k} x\right)-\widehat{L}_{21}^{\prime \prime}(0) G_{1 j}\left(\lambda_{k} x\right)\right], \quad j=1, \ldots, n+1,
$$

where $\bar{C}_{j}$ stands for arbitrary constant that is determined by a chosen for the $j$-th mode normalization condition.

Obviously, to complete solving the free vibration problem of multispan beams with cracks, we need the functions $L_{j r}(\lambda x), r=1,2,3,4$ that are all particular solutions of the equation (2) satisfying conditions (4) inside the beam segment $\left(x_{j-1}, x_{j}\right)$. As shown in [15], such solution could be expressed in the form

$$
L_{j r}(x)=L_{r}(\lambda x)+\sum_{k=1}^{n_{j}} \mu_{j r k} K\left(x-e_{j k}\right), \quad r=1,2,3,4,
$$

where

$$
\begin{aligned}
& \mu_{j r k}=\gamma_{j k}\left[L_{r}^{\prime \prime}\left(\lambda e_{j k}\right)+\sum_{\ell=1}^{k-1} \mu_{r j \ell} S^{\prime \prime}\left(e_{j k}-e_{j \ell}\right)\right], \quad r=1,2,3,4, \\
& L_{1}(x)=0.5(\cosh x+\cos x), \quad L_{2}(x)=0.5(\sinh x-\sin x), \\
& L_{3}(x)=0.5(\cosh x-\cos x), \quad L_{4}(x)=0.5(\sinh x+\sin x),
\end{aligned}
$$




$$
K(x)=\left\{\begin{array}{ll}
0 & \text { for } x \leq 0 \\
S(x) & \text { for } x>0
\end{array}, \quad K^{\prime \prime}(x)=\left\{\begin{array}{ll}
0 & \text { for } x \leq 0 \\
S^{\prime \prime}(x) & \text { for } x>0
\end{array}, \quad S(x)=L_{4}(\lambda x) / \lambda\right.\right.
$$

Eqs. (22) show that for given crack parameters $\left(e_{j k}, \gamma_{j k}, k=1, \ldots, n_{j}\right)$ the so-called crack indexes $\mu_{j r}=\left\{\mu_{j r k}, k=1, \ldots, n_{j}\right\}, r=1,2,3,4$ can be uniquely found from given crack position and depth as

$$
\begin{gathered}
\boldsymbol{\mu}_{j r}=\left[\mathbf{I}-\boldsymbol{\Gamma}\left(\gamma_{j}\right) \mathbf{B}_{j}\left(\lambda, \mathbf{e}_{j}\right)\right]^{-1} \boldsymbol{\Gamma}\left(\gamma_{j}\right) \mathbf{b}_{j r}\left(\lambda, \mathbf{e}_{j}\right), \quad r=1,2,3,4, \\
\boldsymbol{\Gamma}\left(\gamma_{j}\right)=\operatorname{diag}\left\{\gamma_{j 1}, \ldots, \gamma_{j n_{j}}\right\}, \quad \mathbf{B}_{j}(\lambda, \mathbf{e})=\left[b_{\ell k} ; \ell, \quad k=1, \ldots, n_{j}\right], \quad b_{\ell k}=K^{\prime \prime}\left(e_{j \ell}-e_{j k}\right), \\
\mathbf{b}_{j r}=\left\{L_{r}^{\prime \prime}\left(\lambda e_{j 1}\right), \ldots, L_{r}^{\prime \prime}\left(\lambda e_{j n_{j}}\right)\right\}^{T}, \quad \mathbf{e}_{j}=\left(e_{j 1}, \ldots, e_{j n_{j}}\right)^{T}, \quad \gamma_{j}=\left(\gamma_{j 1}, \ldots, \gamma_{j n_{j}}\right)^{T} .
\end{gathered}
$$

Thus, the functions $L_{j r}(\lambda x), r=1,2,3,4 ; j=1, \ldots, n+1$ have been determined and, therefore, the problem of free vibration in multispan beam with arbitrary number of cracks is completely solved. The obtained solution will be illustrated by numerical examples accomplished in subsequent section.

\section{NUMERICAL RESULTS AND DISCUSSION}

\subsection{Effect of support location on natural frequencies of uncracked continuous beams}

In this section, effect of support position on natural frequencies of uncracked continuous beam with various boundary conditions is investigated. First, six lowest frequency parameter of uncracked two-span beam with total length $L=2 \mathrm{~m}$ and different boundary conditions are examined for various support location. The frequencies of simply supported beam with two equal length spans are computed and compared to those given in [6]. The compared results shown in Tab. 1 demonstrate excellent agreement of the frequencies obtained in the present study with the previously published ones. Moreover, it is observed that eigenfrequency spectrum of beam with different boundary conditions (simple supports - SS, clamped ends - CC and clamped-free ends - CF) contains the same frequencies $(3.9266 ; 7.0686 ; 10.2102 ; . .$.$) that are bolded in Tab. 1$. This is typical for twospan beam with the middle support acknowledged as Equal Length Span beam (ELSbeam). The spectrums of two-span beam with Symmetrical Boundary Condition (SBC) and ELS may contain also natural frequencies of individual spans that is not appeared for cantilever beam.

The frequency parameter of two-span beam computed versus location of intermediate support varying from $0.5 \mathrm{~m}$ to $1.5 \mathrm{~m}$ and normalized by those of the ELS-beam are shown in Fig. 1. Obviously, symmetrical intermediate supports in SBC-beam produce the same spectrum of natural frequencies (see Fig. 1(a)). Natural frequencies of odd (even) modes take their maximum (minimum) for the ELS-beam (two-span beam with the middle support). Fundamental frequency of beam with cantilevered boundary condition (CBC) increases with support moving from the left to right end of beam and higher frequencies from the second one get also their maximum (even modes) or minimum (odd modes) for the middle support (see Fig. 1(b)). Note, the maximum and minimum of the 
Table 1. Frequency parameter of intact two-span continuous beam for different positions of support

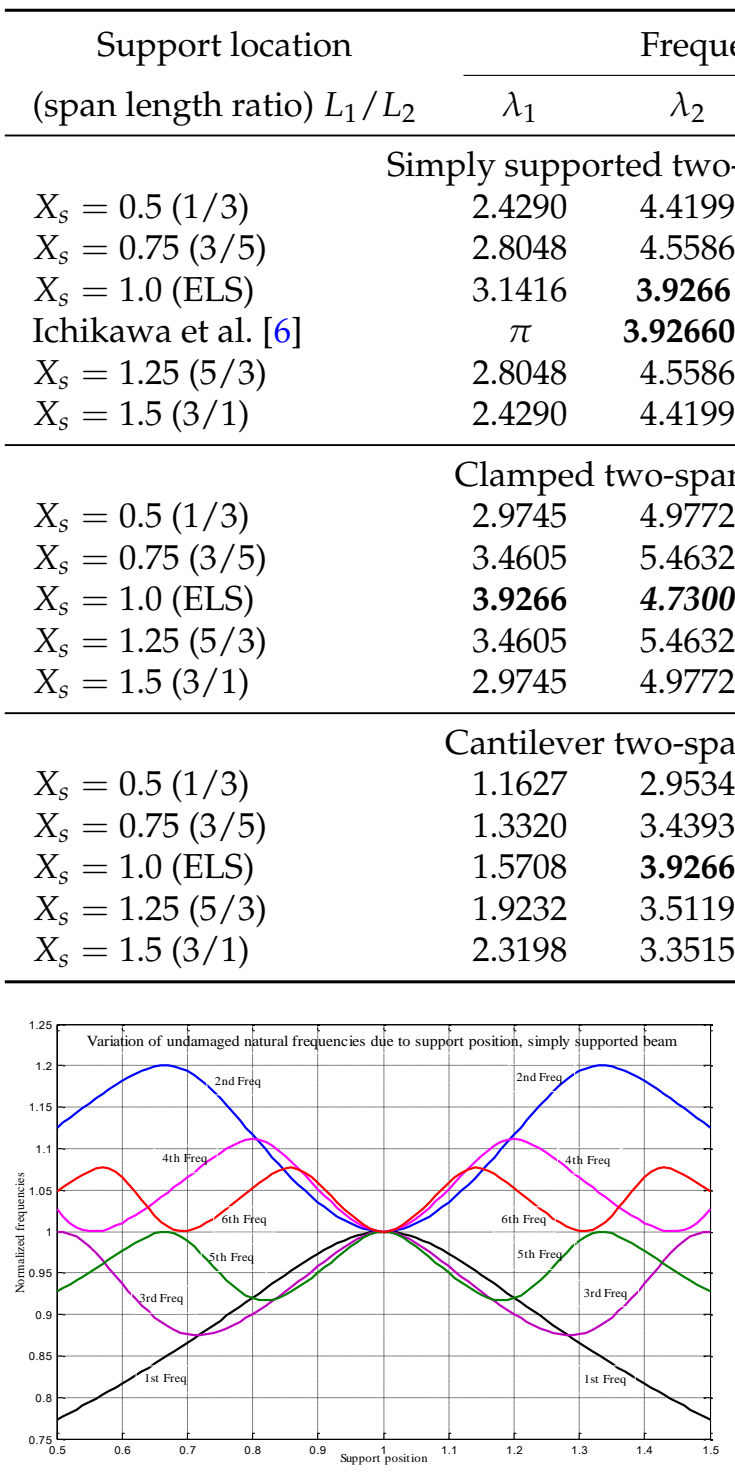

(a)

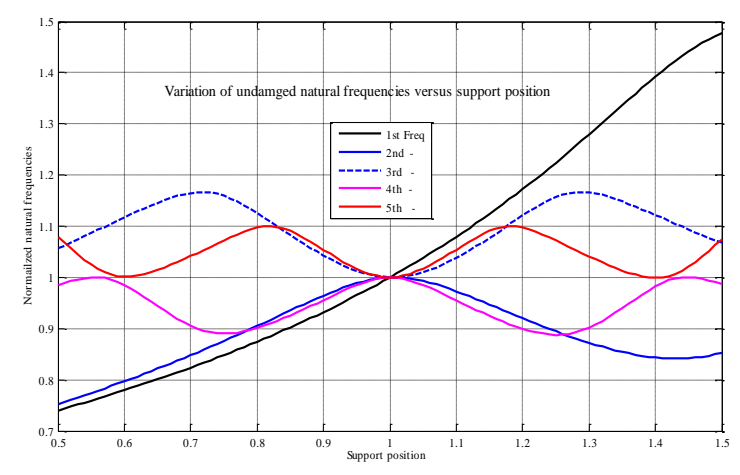

(b)

Fig. 1. Effect of intermediate support location on natural frequencies of (a) SS-beam and (b) CF-beam

natural frequencies may be attained not only in the middle support case but also for other ratios of the span lengths (see Fig. 1).

The frequency parameters of three-span continuous beams with total length $L=3 \mathrm{~m}$ are computed for various location of intermediate supports and the conventional cases of boundary conditions as shown in Tab. 2 . The common frequencies typical for two-span 
Table 2. Effect of supports location on natural frequencies for intact three-span continuous beams

\begin{tabular}{|c|c|c|c|c|c|c|c|}
\hline \multicolumn{2}{|c|}{ Support location } & \multicolumn{6}{|c|}{ Frequency parameter, $\lambda=\left(\omega^{2} \rho A / E I\right)^{1 / 4}$} \\
\hline$X_{1}$ & $X_{2}$ & $\lambda_{1}$ & $\lambda_{2}$ & $\lambda_{3}$ & $\lambda_{4}$ & $\lambda_{5}$ & $\lambda_{6}$ \\
\hline \multicolumn{8}{|c|}{ Simply supported three-span continuous beam $(L=3)$} \\
\hline 1.25 & 1.75 & 2.8220 & 2.9838 & 5.1738 & 5.4154 & 7.2104 & 7.8495 \\
\hline 1.0 & 2.0 & 3.1416 & $\underline{3.5564}$ & 4.2975 & 6.2832 & $\underline{6.7076}$ & 7.4295 \\
\hline 0.75 & 2.25 & 2.6177 & 4.1888 & 4.7124 & 5.2355 & 6.8068 & 8.3776 \\
\hline 0.5 & 2.5 & 2.1079 & 3.5564 & 5.0021 & 6.2832 & 6.9659 & 7.4295 \\
\hline 0.5 & 2.0 & 2.6029 & 3.5651 & 4.7111 & 6.2832 & 6.8067 & 7.4297 \\
\hline 0.75 & 2.0 & 2.9206 & 3.6847 & 4.6569 & 5.7073 & 6.7198 & 8.0243 \\
\hline 1.25 & 2.0 & 2.8194 & 3.4926 & 4.9118 & 5.6484 & 6.7504 & 7.8145 \\
\hline 1.5 & 2.0 & 2.4376 & 3.5805 & 4.4556 & 6.2832 & 6.6398 & 7.8648 \\
\hline \multicolumn{8}{|c|}{ Clamped three-span continuous beam $(L=3)$} \\
\hline 1.25 & 1.75 & 3.4223 & 3.6011 & 5.7411 & 6.0193 & 7.5635 & 8.4584 \\
\hline 1.0 & 2.0 & $\underline{3.5564}$ & 4.2975 & 4.7300 & $\underline{6.7076}$ & 7.4295 & 7.8532 \\
\hline 0.75 & 2.25 & 2.7060 & 4.5243 & 5.5964 & $\overline{5.9511}$ & 6.9854 & 8.7272 \\
\hline 0.5 & 2.5 & 2.1546 & 3.6195 & 5.1026 & 6.5608 & 7.8537 & 8.5558 \\
\hline 0.5 & 2.0 & 2.7073 & 4.1808 & 4.8968 & 6.6237 & 7.5051 & 8.3885 \\
\hline 0.75 & 2.0 & 3.1041 & 4.3305 & 5.3487 & 6.1078 & 7.3669 & 8.2585 \\
\hline 1.25 & 2.0 & 3.4075 & 4.1887 & 5.2465 & 6.1296 & 7.4393 & 8.3779 \\
\hline 1.5 & 2.0 & 2.9487 & 4.3250 & 4.9649 & 6.7682 & 7.2774 & 8.2037 \\
\hline \multicolumn{8}{|c|}{ Cantilever three-span continuous beam $(L=3)$} \\
\hline 1.25 & 1.75 & 1.7090 & 3.5148 & 5.8280 & 6.6665 & 8.0064 & 8.8420 \\
\hline 1.0 & 2.0 & 1.5414 & 3.5685 & 4.2845 & 4.7185 & 6.7071 & 7.4301 \\
\hline 0.75 & 2.25 & 2.3196 & 3.0799 & 4.6202 & 5.7452 & 6.5278 & 7.2035 \\
\hline 0.5 & 2.5 & 1.9946 & 3.3385 & 4.1643 & 5.2258 & 6.6363 & 7.9767 \\
\hline 0.5 & 2.0 & 1.6929 & 2.8227 & 4.5709 & 5.3023 & 6.7174 & 8.0679 \\
\hline 0.75 & 2.0 & 1.5483 & 3.1686 & 4.8048 & 5.4529 & 6.1584 & 7.8796 \\
\hline 1.25 & 2.0 & 1.6451 & 3.4169 & 4.5080 & 5.4031 & 6.1671 & 8.2517 \\
\hline 1.5 & 2.0 & 1.9116 & 2.9577 & 4.9391 & 6.4516 & 7.0733 & 8.2689 \\
\hline
\end{tabular}

ELS-beams of all the boundary conditions are now observed only for three-span ELSbeams with SBC $(3.5564,6.7076,9.8488, \ldots)$. Also, there are found natural frequencies of individual spans in the eigenfrequency spectrum only for three-span ELS-beams with simply supported ends. The frequencies are not monotonically varying with increasing length of the intermediate span (decreasing length of two boundary spans) but they may attain their maximum or minimum dependently on the number of modes. This is true even for the case of fixed one support while the other is moving either to the left or to the right. Observing changes in frequency parameter of three-span continuous beams induced by variation of supports location shows that the frequency changes are still of waveform only for SS- and CC-beams.

\subsection{Effect of support location on natural frequencies of cracked continuous beams}

This section is devoted to study effect of support location and cracks (position and depth) on natural frequencies of two and three-span beams. First, ratios of cracked to 
intact frequency parameter of the beams with single crack running over the beam length are computed for different locations of supports and crack depths. The ratios of three lowest frequency parameters have been computed as function of crack position for various crack depth and support location presented respectively on the left and on the right of Figs. 2-4 for two-span beams and Figs. 5-7 for three-span beams with different various boundary conditions.
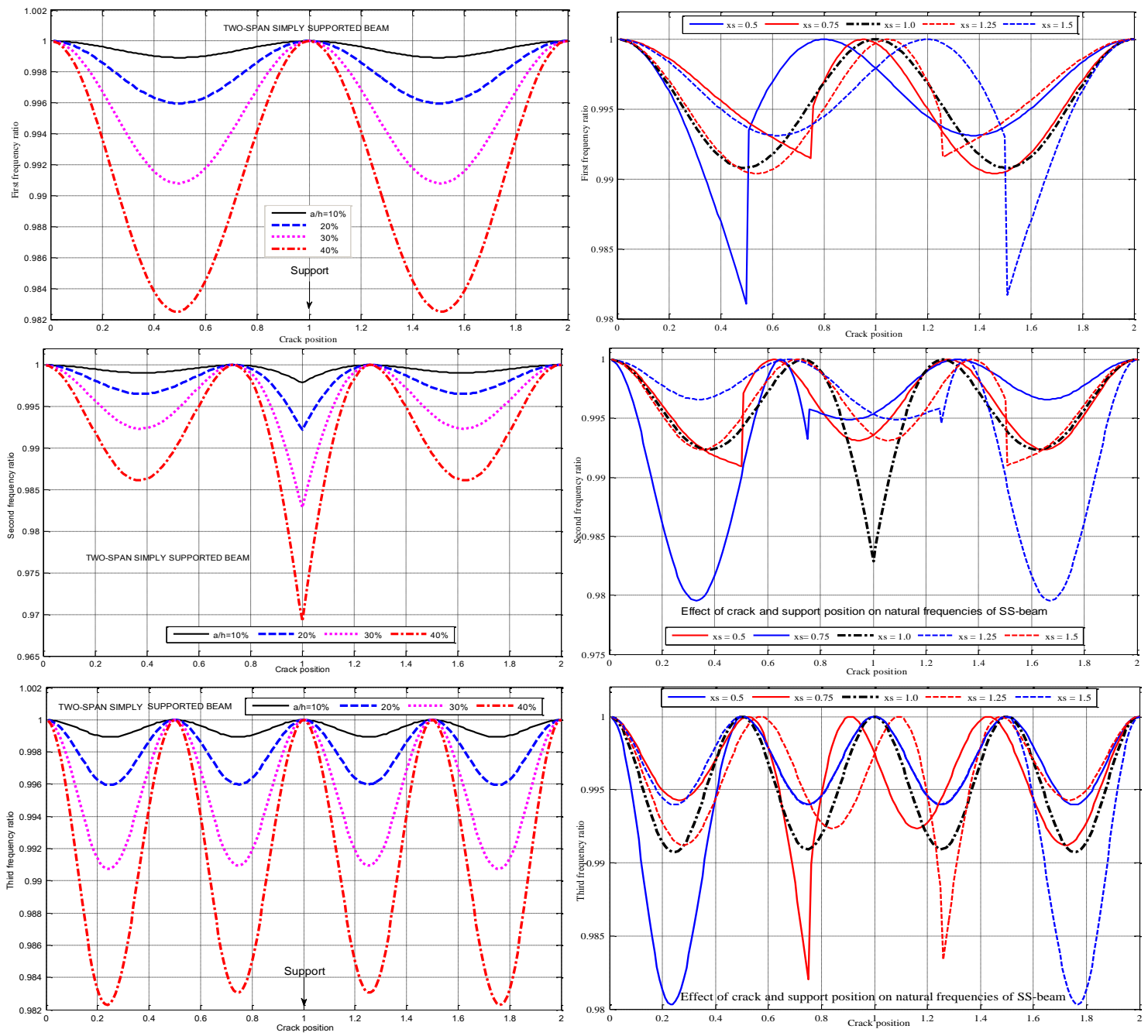

Fig. 2. Effect of crack depth (left) and support location (right) on natural frequencies of two-span SS-beam

The graphs shown in Figs. 2-7 allow one to make some remarks as follow: (1) There are observed so-called frequency nodes (the points on the beam, crack occurred at which makes no effect on frequency of a certain mode) that are coinciding with the support 

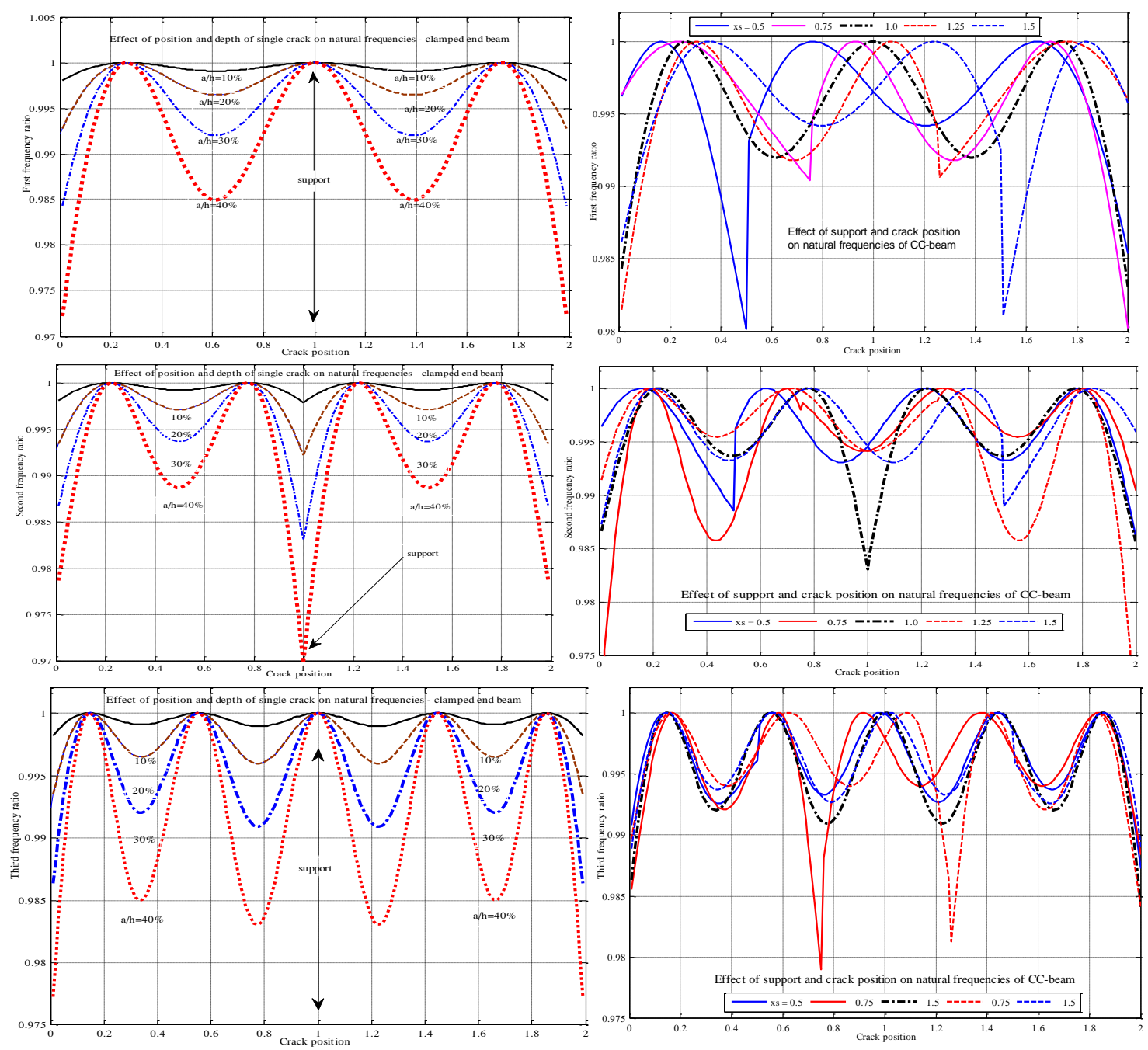

Fig. 3. Effect of crack depth (left) and support location (right) on natural frequencies of two-span CC-beam

location for the odd modes of two-span ELS-beam with SBCs and event modes for ELSbeams with Cantilever Boundary Conditions (CBC); (2) Positions of the nodes are certainly dependent on the support location, they intend to move from a referenced site (of ELS-beams) to the most near support location; (3) Crack at support locations makes the natural frequencies of every mode for three-span beams and event (odd) modes for twospan SBC(CBC)-beams got largest reduction; (4) The frequency ratios undertake a jump as crack occurs at the support location and height of the jump depends on how far the support is deviated from the support locations of ELS-beams which have no jump at the support location; (5) As whenever, increasing depth of crack leads all natural frequencies to be more reduced by the crack. 

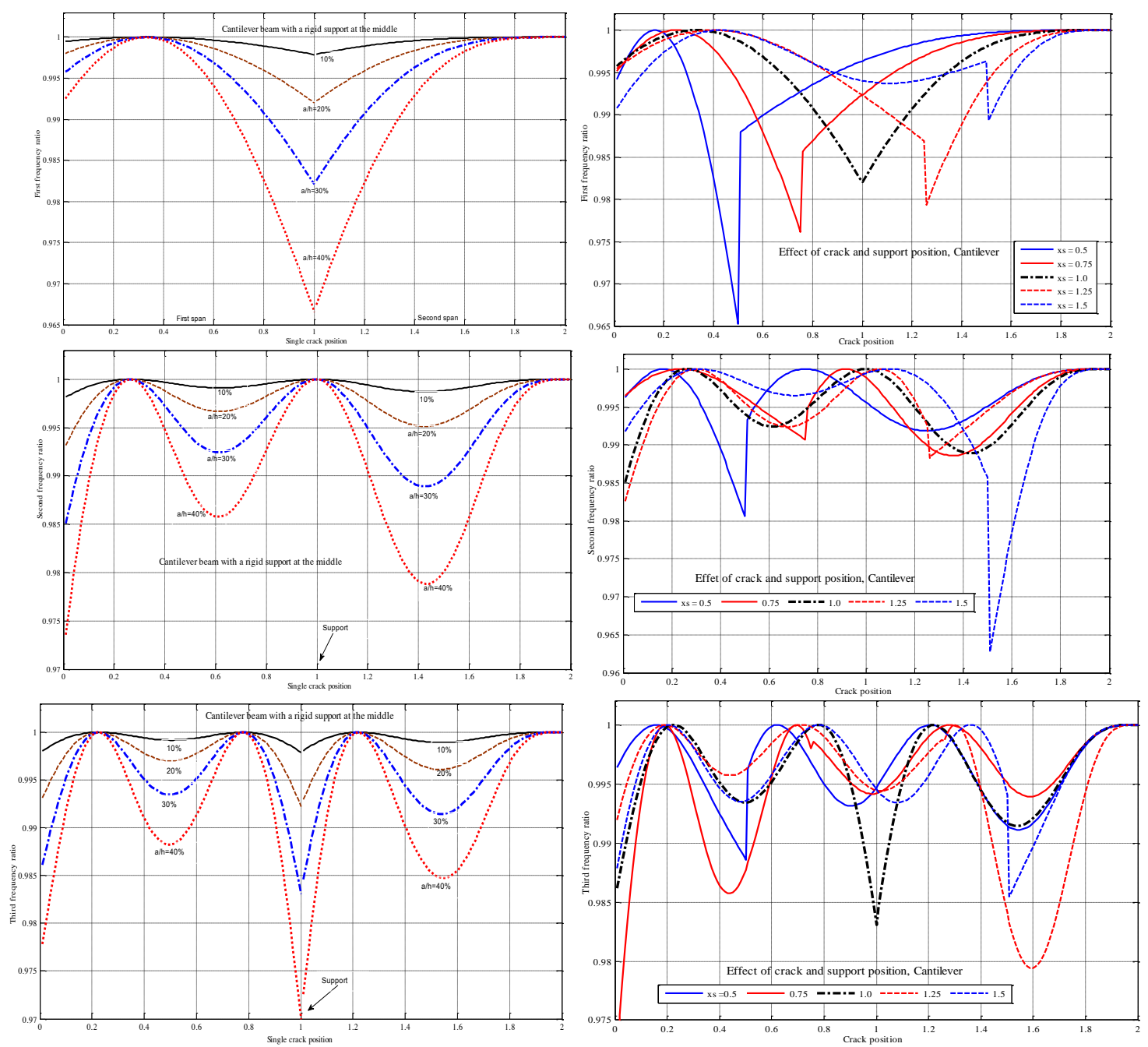

Fig. 4. Effect of crack depth (left) and support location (right) on natural frequencies of two-span CF-beam
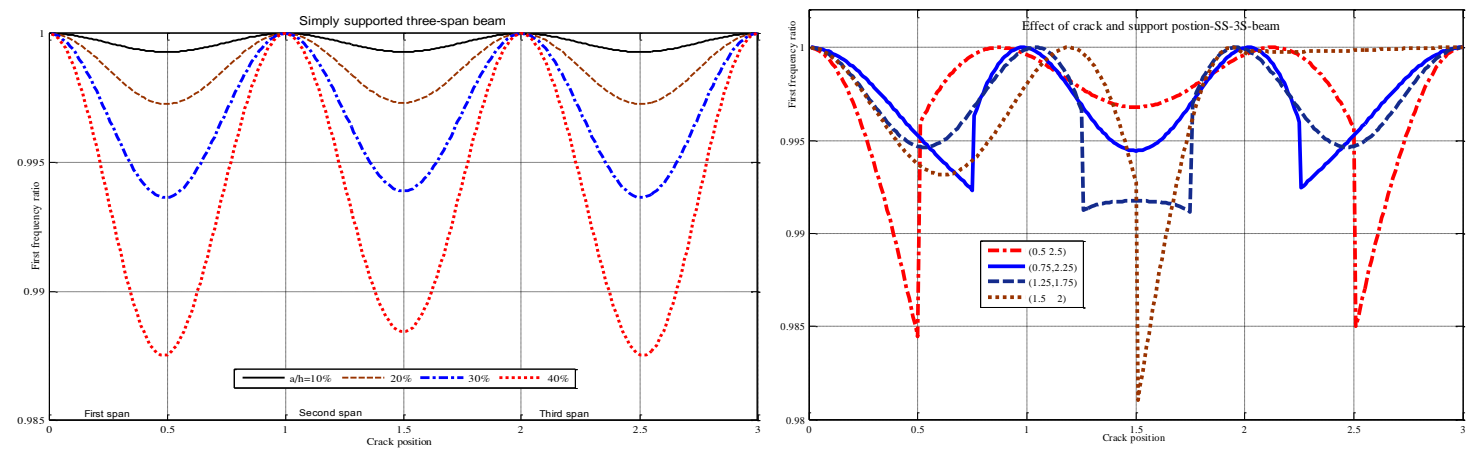

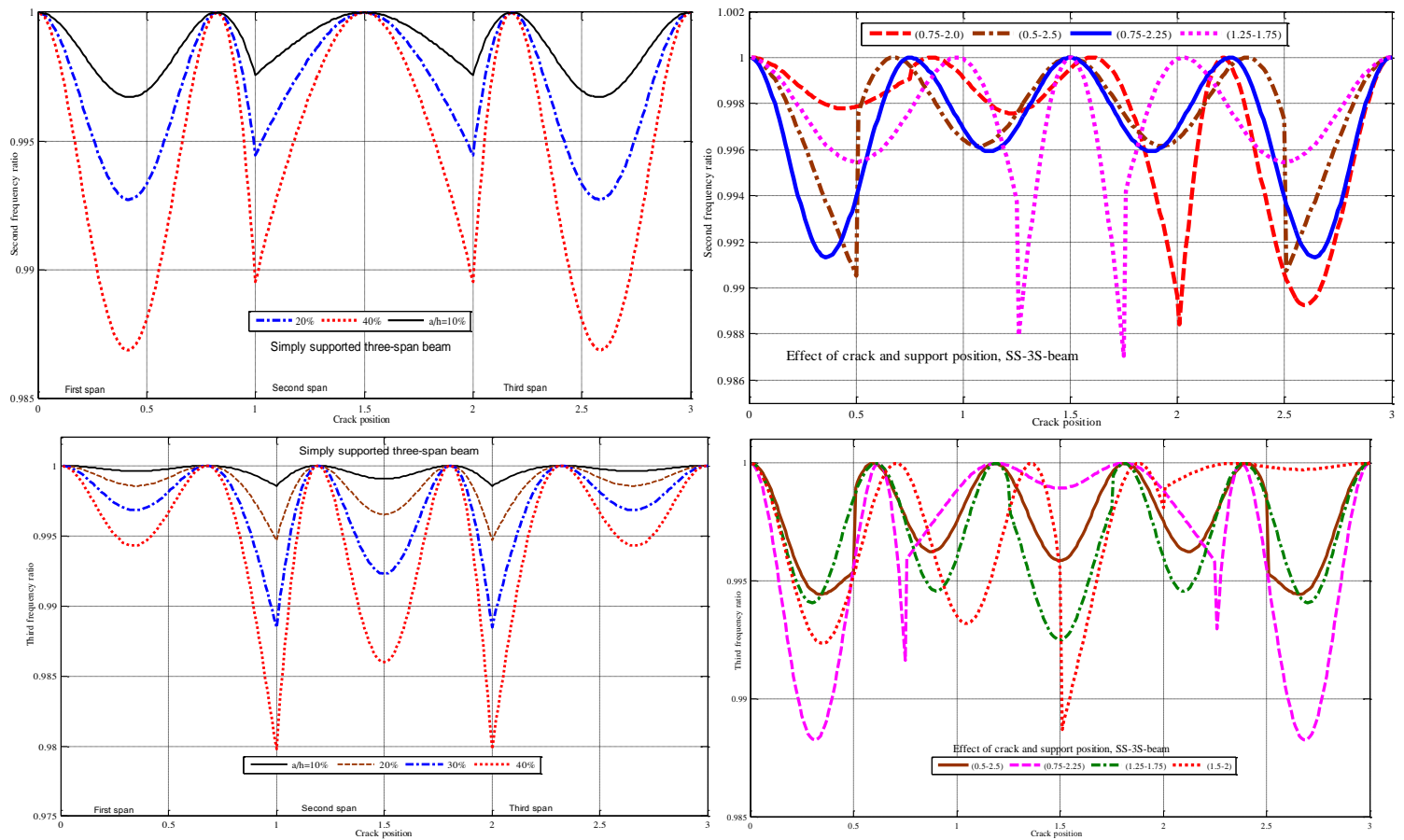

Fig. 5. Effect of crack depth (left) and support location (right) on natural frequencies of three-span SS-beam
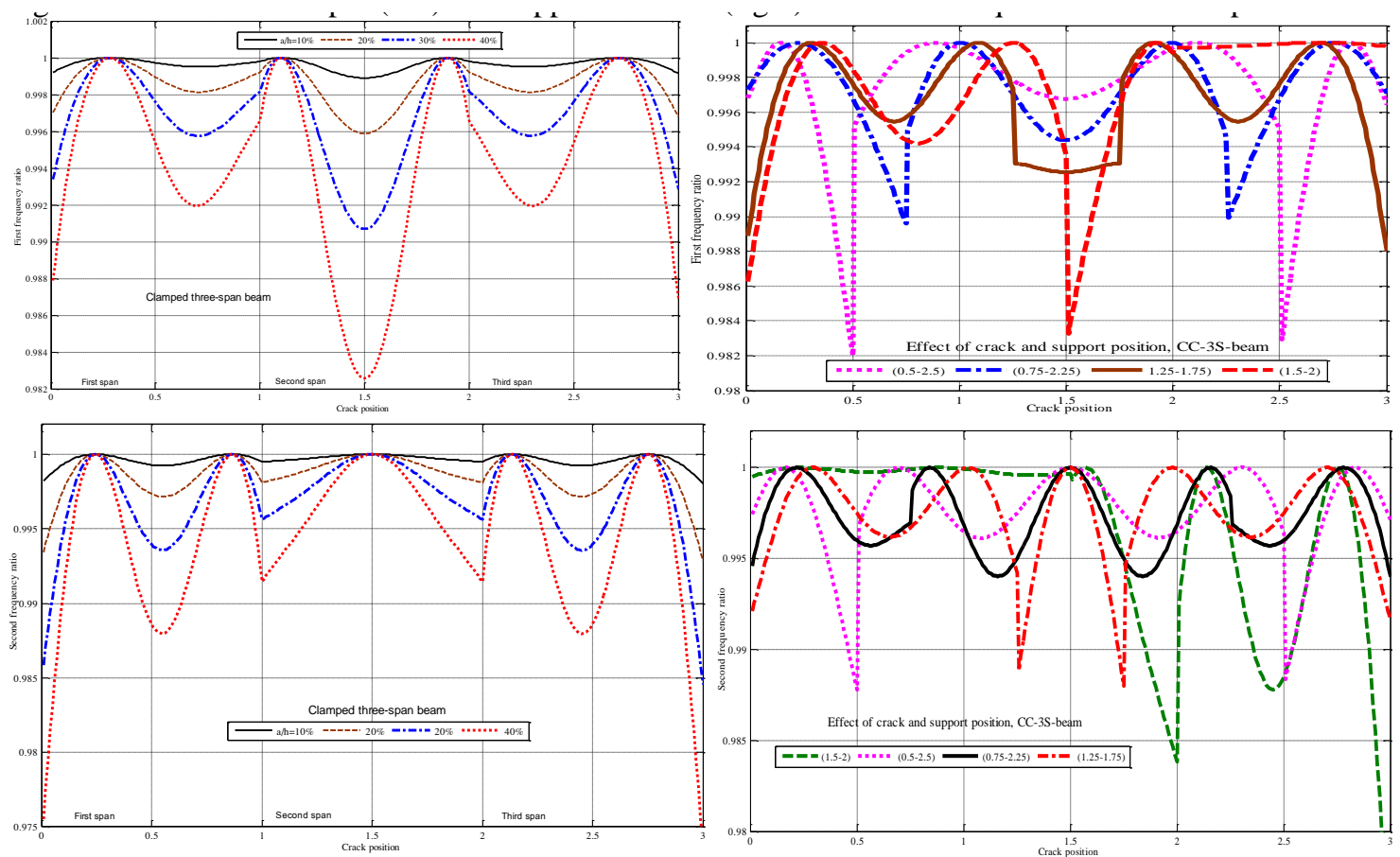

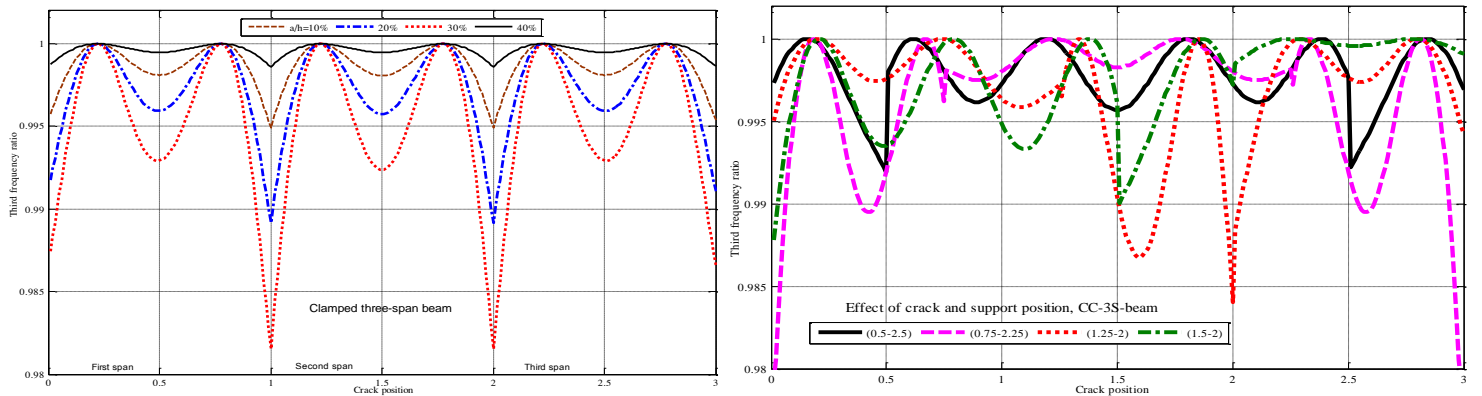

Fig. 6. Effect of crack depth (left) and support location (right) on natural frequencies of three-span CC-beam
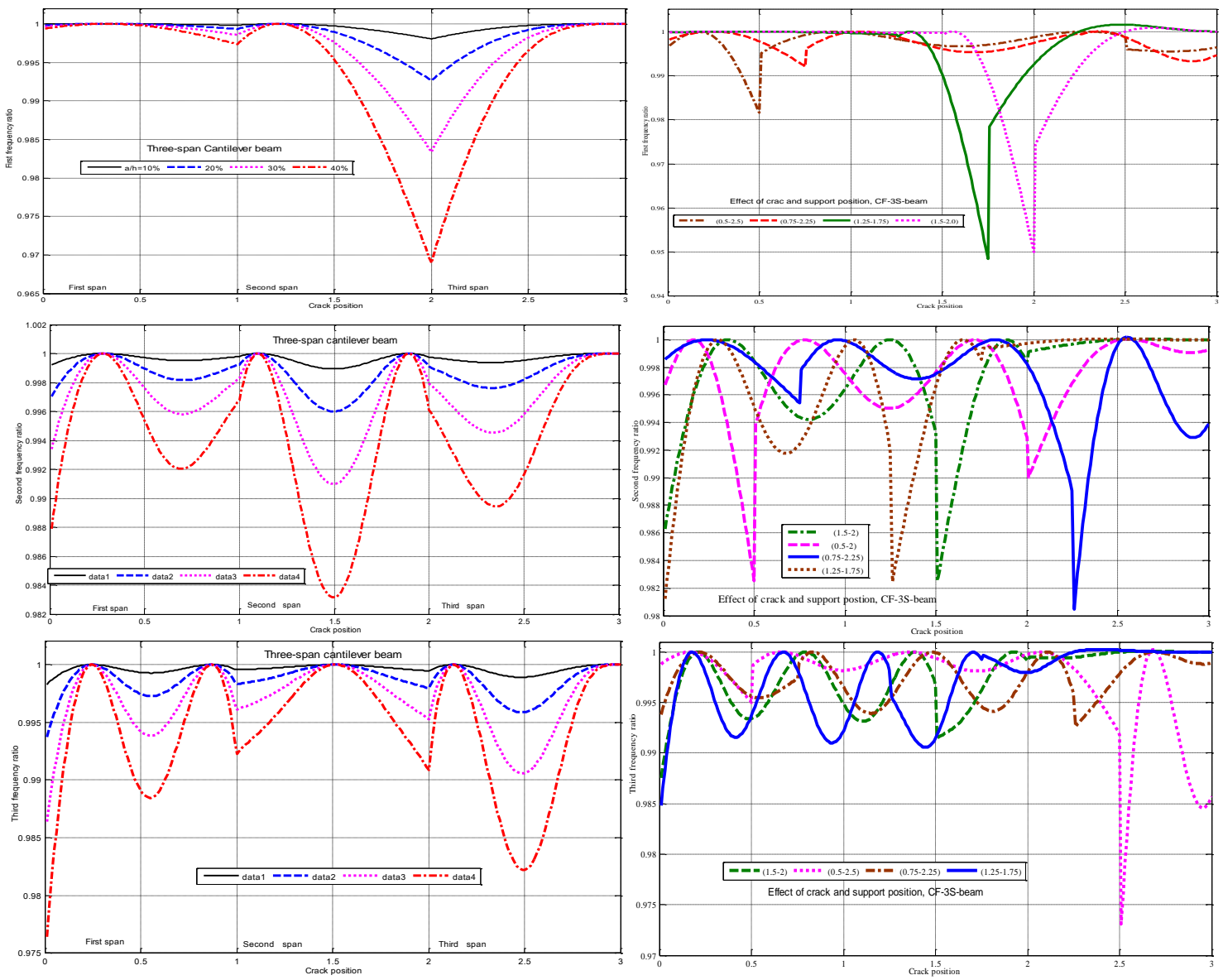

Fig. 7. Effect of crack depth (left) and support location (right) on natural frequencies of three-span CF-beam 
The effect of multiple cracks on natural frequencies of two-span continuous beam is shown in Tab. 3. It is observed in Tab. 3 that single crack at the middle of both two spans causes more reduction of first and second frequencies than double cracks located near the supports but the double cracks make more effect on two subsequent frequencies than the single crack at the span middle. This can be verified by the graphs given in Figs. 2-4 that show the crack positions where natural frequencies get their maximum and minimum reduction. Furthermore, it can be noticed from the Table that for two-span cantilever beam cracks occurred near the clamped end make less effect on the first two frequencies than cracks occurred near the free end. This is dissimilar to the single span cantilever beam and typical for two-span cantilever beam.

Table 3. Frequency parameter of continuous two-span beam with cracks and middle support

\begin{tabular}{|c|c|c|c|c|c|c|c|c|c|}
\hline \multicolumn{4}{|c|}{ Crack positions } & $\lambda_{1}$ & $\lambda_{2}$ & $\lambda_{3}$ & $\lambda_{4}$ & $\lambda_{5}$ & $\lambda_{6}$ \\
\hline \multicolumn{10}{|c|}{ Simply supported beam } \\
\hline \multicolumn{4}{|c|}{ No crack } & 3.1416 & 3.9266 & 6.2832 & 7.0686 & 9.4248 & 10.2102 \\
\hline \multicolumn{2}{|c|}{$1^{\text {st }} \mathrm{span}$} & \multicolumn{2}{|c|}{$2^{\text {nd }}$ span } & \multicolumn{6}{|c|}{$E=2 e 11, h=0.0, b=0.0, a / h=0.3, L_{1}=L_{2}=1$} \\
\hline \multicolumn{2}{|c|}{ No crack } & 1.2 & 1.8 & 3.1318 & 3.9230 & 6.2324 & 7.0584 & 9.3479 & 10.1521 \\
\hline \multicolumn{2}{|c|}{0.5} & 1.2 & 1.8 & 3.1024 & 3.9033 & 6.2324 & 7.0499 & 9.2748 & 10.0714 \\
\hline 0.2 & 0.8 & 1.2 & 1.8 & 3.1215 & 3.9065 & 6.1819 & 6.9970 & 9.2842 & 10.0800 \\
\hline 0.2 & 0.8 & \multicolumn{2}{|c|}{1.5} & 3.1032 & 3.8861 & 6.2292 & 7.0031 & 9.2746 & 10.0707 \\
\hline 0.2 & 0.8 & \multicolumn{2}{|c|}{ No crack } & 3.1314 & 3.9098 & 6.2292 & 7.0109 & 9.3499 & 10.1494 \\
\hline \multicolumn{10}{|c|}{ Cantilever beam } \\
\hline \multicolumn{4}{|c|}{ No crack } & 1.5708 & 3.9266 & 4.7124 & 7.0686 & 7.8540 & 10.2120 \\
\hline \multirow{2}{*}{\multicolumn{2}{|c|}{$\begin{array}{c}\text { No crack } \\
0.5\end{array}$}} & 1.2 & 1.8 & 1.5561 & 3.9067 & 4.7118 & 7.0072 & 7.8338 & 10.1373 \\
\hline & & 1.2 & 1.8 & 1.5543 & 3.8834 & 4.6812 & 6.9988 & 7.8338 & 10.0704 \\
\hline 0.2 & 0.8 & 1.2 & 1.8 & 1.5550 & 3.9033 & 4.7110 & 6.9978 & 7.8106 & 10.0799 \\
\hline 0.2 & 0.8 & \multicolumn{2}{|c|}{1.5} & 1.5666 & 3.8829 & 4.6723 & 7.0477 & 7.8322 & 10.0727 \\
\hline 0.2 & 0.8 & \multicolumn{2}{|c|}{ No crack } & 1.5696 & 3.9233 & 4.7115 & 7.0576 & 7.8323 & 10.1402 \\
\hline \multicolumn{10}{|c|}{ Clamped en } \\
\hline \multicolumn{4}{|c|}{ No crack } & 3.9266 & 4.7300 & 7.0686 & 7.8532 & 10.2102 & 10.9956 \\
\hline No & ack & 1.2 & 1.8 & 3.9102 & 4.7292 & 7.0065 & 7.8329 & 10.1374 & 10.9265 \\
\hline \multicolumn{2}{|c|}{0.5} & 1.2 & 1.8 & 3.8855 & 4.6996 & 6.9980 & 7.8329 & 10.0705 & 10.8260 \\
\hline 0.2 & 0.8 & 1.2 & 1.8 & 3.9065 & 4.7285 & 6.9970 & 7.8096 & 10.0800 & 10.8424 \\
\hline 0.2 & 0.8 & \multicolumn{2}{|c|}{1.5} & 3.8986 & 4.6992 & 7.0496 & 7.8315 & 10.0712 & 10.8266 \\
\hline 0.2 & 0.8 & \multicolumn{2}{|c|}{ No crack } & 3.9231 & 4.7293 & 7.0576 & 7.8315 & 10.1402 & 10.9240 \\
\hline
\end{tabular}

Effect of multiple cracks on natural frequencies of three-span ELS-beam with different boundary conditions is examined for crack scenarios listed in Tab. 4 . Since the effect of single crack on natural frequencies of three-span beam has been shown in Figs. 5-7, herein, six lowest natural frequencies of the beam are computed only for multiple cracks starting from the case of double cracks at the supports and inside every span. Results of the computation given in Tab. 5 enable to make the following notes for the multiple cracked three-span beam: (1) Double cracks occurred at two equidistant supports in 
Table 4. Multiple crack scenarios in three-span ELS-beam $(L=3.0 \mathrm{~m})$

\begin{tabular}{|c|c|c|c|c|c|c|c|}
\hline \multicolumn{8}{|c|}{ Positions of cracks in spans; depth of all cracks is 30\% } \\
\hline Notations & Number of cracks & \multicolumn{2}{|c|}{ First span } & \multicolumn{2}{|c|}{ Second span } & \multicolumn{2}{|c|}{ Third span } \\
\hline $1-(2-0-0)$ & 2 & 0.25 & 0.75 & \multicolumn{2}{|c|}{ No crack } & \multirow{2}{*}{\multicolumn{2}{|c|}{$\begin{array}{l}\text { No crack } \\
\text { No crack }\end{array}$}} \\
\hline $2-(0-2-0)$ & 2 & \multicolumn{2}{|c|}{ No crack } & 1.25 & 1.75 & & \\
\hline $3-(0-0-2)$ & 2 & \multicolumn{2}{|c|}{ No crack } & \multicolumn{2}{|c|}{ No crack } & 2.25 & 2.75 \\
\hline $4-(1-1-1)$ & 3 & \multicolumn{2}{|c|}{0.5} & \multicolumn{2}{|c|}{1.5} & \multicolumn{2}{|c|}{2.5} \\
\hline $5-(1-2-1)$ & 4 & \multicolumn{2}{|c|}{0.5} & 1.25 & 1.75 & \multicolumn{2}{|c|}{2.5} \\
\hline $6-(2-0-2)$ & 4 & 0.25 & 0.75 & \multicolumn{2}{|c|}{ No crack } & 2.25 & 2.75 \\
\hline $7-(2-1-2)$ & 5 & 0.25 & 0.75 & \multicolumn{2}{|c|}{1.5} & 2.25 & 2.75 \\
\hline $8-(2-2-2)$ & 6 & 0.25 & 0.75 & 1.25 & 1.75 & 2.25 & 2.75 \\
\hline
\end{tabular}

Table 5. Effect of multiple cracks on natural frequencies of three-equal-length-span continuous beam

\begin{tabular}{|c|c|c|c|c|c|c|c|c|c|c|}
\hline \multirow{2}{*}{$\begin{array}{c}\text { Freq. } \\
\text { Number } \\
(\lambda)\end{array}$} & \multicolumn{10}{|c|}{ Multi-crack scenario cases } \\
\hline & $\begin{array}{l}\text { No } \\
\text { crack }\end{array}$ & $\begin{array}{l}\text { Cracks at } \\
\text { supports }\end{array}$ & $\begin{array}{c}1 \\
(2-0-0)\end{array}$ & $\begin{array}{c}2 \\
(0-2-0)\end{array}$ & $\begin{array}{c}3 \\
(0-0-2)\end{array}$ & $\begin{array}{c}4 \\
(1-1-1)\end{array}$ & $\begin{array}{c}5 \\
(1-2-1)\end{array}$ & $\begin{array}{c}6 \\
(2-0-2)\end{array}$ & $\begin{array}{c}7 \\
(2-1-2)\end{array}$ & $\begin{array}{c}8 \\
(2-2-2)\end{array}$ \\
\hline \multicolumn{11}{|c|}{ Simply supported beam (SS): $L_{1}=L_{2}=L_{3}=1.0 \mathrm{~m}$} \\
\hline 1 & 3.1416 & 3.1416 & 3.1223 & 3.1230 & 3.1223 & 3.0853 & 3.0853 & 3.1042 & 3.0853 & 3.0853 \\
\hline 2 & 3.5564 & 3.5196 & 3.5375 & 3.5434 & 3.5375 & 3.5074 & 3.4944 & 3.5176 & 3.5176 & 3.5046 \\
\hline 3 & 4.2975 & 4.1960 & 4.2831 & 4.2912 & & 4.2472 & 4.2744 & 4.2686 & 4.2357 & 4.2619 \\
\hline 4 & 6.2832 & 6.2832 & 6.1939 & 6.2047 & 6.1939 & 6.2832 & 6.2046 & 6.1333 & 6.1333 & 6.0671 \\
\hline 5 & 6.7076 & 6.6408 & 6.6289 & 6.7059 & 6.6289 & 6.6953 & 6.7017 & 6.5245 & 6.5158 & 6.5230 \\
\hline 6 & 7.4295 & 7.2631 & 7.4032 & 7.3233 & 7.4032 & 7.4146 & 7.3092 & 7.3738 & 7.3738 & 7.2552 \\
\hline \multicolumn{11}{|c|}{ Clamped end beam (CC): $L_{1}=L_{2}=L_{3}=1.0 \mathrm{~m}$} \\
\hline 1 & 3.5564 & 3.5431 & 3.5413 & 3.5352 & 3.5413 & 3.5074 & 3.5186 & 3.5265 & 3.4935 & 3.5046 \\
\hline 2 & 4.2975 & 4.2637 & 4.2887 & 4.2807 & 4.2887 & 4.2472 & 4.2309 & 4.2795 & 4.2795 & 4.2619 \\
\hline 3 & 4.7300 & 4.6248 & 4.7290 & 4.7290 & 4.729 & 4.6687 & 4.6883 & 4.7279 & 4.7076 & 4.7268 \\
\hline 4 & 6.7076 & 6.6816 & 6.6700 & 6.5801 & 6.6700 & 6.6953 & 6.5675 & 6.6379 & 6.6379 & 6.5230 \\
\hline 5 & 7.4295 & 7.3746 & 7.3379 & 7.4258 & 7.3379 & 7.4146 & 7.4208 & 7.2583 & 7.2491 & 7.2552 \\
\hline 6 & 7.8532 & 7.6890 & 7.8049 & 7.7987 & 7.8049 & 7.8532 & 7.7987 & 7.7391 & 7.7391 & 7.6725 \\
\hline \multicolumn{11}{|c|}{ Cantilever beam (CF): $L_{1}=L_{2}=L_{3}=1.0 \mathrm{~m}$} \\
\hline 1 & 1.5414 & 1.5138 & 1.5405 & 1.5288 & 1.5304 & 1.5348 & 1.5260 & 1.5294 & 1.5258 & 1.5172 \\
\hline 2 & 3.5685 & 3.5547 & 3.5536 & 3.5482 & 3.5479 & 3.5144 & 3.5253 & 3.5335 & 3.5017 & 3.5126 \\
\hline 3 & 4.2845 & 4.2512 & 4.2757 & 4.2681 & 4.2631 & 4.2216 & 4.2059 & 4.2540 & 4.2539 & 4.2370 \\
\hline 4 & 4.7185 & 4.6133 & 4.7173 & 4.7174 & 4.7087 & 4.6504 & 4.6702 & 4.7074 & 4.6868 & 4.7061 \\
\hline 5 & 6.7071 & & 6.6695 & 6.5795 & 6.6552 & 6.6936 & 6.5656 & 6.6248 & 6.6248 & 6.5115 \\
\hline 6 & 7.4301 & 7.3751 & 7.3383 & 7.4263 & 7.3125 & 7.4143 & 7.4205 & 7.2352 & 7.2261 & 7.2318 \\
\hline
\end{tabular}

three-span beam do not change the first and fourth natural frequencies of simply supported beam that can be observed also in Fig. 5; (2) Symmetric cracks produce the same eigenfrequency spectrum of beam with symmetric boundary conditions (cases 1 and 3 ) and multiple cracks happened at intermediate span make all frequencies more reduced than those happened solely at the boundary spans of SBC-beam; (3) For cantilever beam, 
multiple cracks near the free end make more effect on natural frequencies than those located near the clamped end; (4) Increasing number of cracks, in general, leads natural frequencies to more reduced, except the specific cases of crack positions (cases 4, 5, 7 and 8 ) when the number of cracks equals to $3-4-5-6$, the fundamental frequency is the same. This can be explained by the fact that cracks occurred at the middle of spans $(0.5 ; 1.5$ and 2.5) cause the frequency change in two times greater than the change caused by cracks at the positions $0.25 ; 0.75 ; 1.25 ; 1.75 ; 2.25,2.75$ as shown in Fig. 5 . So, the frequency change caused by three cracks at the middle of spans equals to the change caused by six cracks at the symmetric locations $0.25 ; 0.75 ; 1.25 ; 1.75 ; 2.25,2.75$.

\section{CONCLUSION}

In this study, a simplified method has been proposed to calculate natural frequencies of multiple cracked continuous beam with intermediate rigid supports and various boundary conditions. Natural frequencies of two-span (single support) and three-span (two supports) beams with multiple cracks were numerically examined in dependence upon location of supports and crack position and depth. It is discovered that for an intact two-span continuous beam eigenfrequency spectrum may contain natural frequencies of individual spans and common frequencies for all the boundary conditions such as simple supports (SS), clamped ends (CC) and cantilever (CF). The latter frequencies are typically caused by a single support at the middle of a continuous beam, therefore, their presence in the eigenfrequency spectrum of a beam is an obvious indicator for existence of a rigid support for the beam. However, the typical frequencies disappear for two-span beam with cracks and support located not at the beam middle. For three-span continuous beam, the individual frequencies are observed only for simply supported intact beam and the typical frequencies are found only for the beams with symmetric boundary conditions (SS and CC). All the specific frequencies become disappeared for cracked three-span beams of all the boundary conditions. Furthermore, likely to the single span beam, there are exist positions on a multispan continuous beams crack occurred at which do not change a specific frequency. Such positions that are usually called frequency node of the associated mode depend also on support location in the beam. The middle support is the frequency node of odd modes for two-span beam with symmetric boundary conditions and even modes of two-span cantilever beam. The equidistant supports in three-span beams are frequency node of first, fourth, ... modes only for simply supported beams. Finally, location of intermediate supports in a continuous beam makes significant effect on eigenfrequency spectrum of the beam in both cases of with and without cracks. The continuous beams with equidistant supports have either maximum or minimum frequencies dependently on mode number and boundary conditions. Frequency nodes and sensitivity of natural frequencies to cracks are all considerably dependent also on the location of supports in a continuous beam.

\section{ACKNOWLEDGEMENTS}

The first author is thankful to VNU-UET (Grant No. CN17.05) and second author acknowledges NAFOSTED (Grant No.107.01-2015.20) for financial supports in completing this work. 


\section{REFERENCES}

[1] Y. K. Lin. Free vibrations of a continuous beam on elastic supports. International Journal of Mechanical Sciences, 4, (5), (1962), pp. 409-423. doi:10.1016/s0020-7403(62)80027-7.

[2] H. P. Lin and S. C. Chang. Free vibration analysis of multi-span beams with intermediate flexible constraints. Journal of Sound and Vibration, 281, (1-2), (2005), pp. 155-169. doi:10.1016/j.jsv.2004.01.010.

[3] D. Zhou. Free vibration of multi-span Timoshenko beams using static Timoshenko beam functions. Journal of Sound and Vibration, 241, (4), (2001), pp. 725-734. doi:10.1006/jsvi.2000.3266.

[4] K. Saeedi and R. B. Bhat. Clustered natural frequencies in multi-span beams with constrained characteristic functions. Shock and Vibration, 18, (5), (2011), pp. 697-707. doi:10.1155/2011/940461.

[5] D. Y. Zheng, Y. K. Cheung, F. T. K. Au, and Y. S. Cheng. Vibration of multi-span non-uniform beams under moving loads by using modified beam vibration functions. Journal of Sound and Vibration, 212, (3), (1998), pp. 455-467. doi:10.1006/jsvi.1997.1435.

[6] M. Ichikawa, Y. Miyakawa, and A. Matsuda. Vibration analysis of the continuous beam subjected to a moving mass. Journal of Sound and Vibration, 230, (3), (2000), pp. 493-506. doi:10.1006/jsvi.1999.2625.

[7] Y. Yesilce and O. Demirdag. Effect of axial force on free vibration of Timoshenko multi-span beam carrying multiple spring-mass systems. International Journal of Mechanical Sciences, 50, (6), (2008), pp. 995-1003. doi:10.1016/j.ijmecsci.2008.03.001.

[8] Y. Yesilce. Free and forced vibrations of an axially-loaded Timoshenko multi-span beam carrying a number of various concentrated elements. Shock and Vibration, 19, (4), (2012), pp. 735752. doi:10.1155/2012/579287.

[9] K. Henchi, M. Fafard, G. Dhatt, and M. Talbot. Dynamic behaviour of multi-span beams under moving loads. Journal of Sound and Vibration, 199, (1), (1997), pp. 33-50. doi:10.1006/jsvi.1996.0628.

[10] N. Azizi, M. M. Saadatpour, and M. Mahzoon. Using spectral element method for analyzing continuous beams and bridges subjected to a moving load. Applied Mathematical Modelling, 36, (8), (2012), pp. 3580-3592. doi:10.1016/j.apm.2011.10.019.

[11] H. B. Liu, H. H. Nguyen, and Y. M. Xiang. Vibration analysis of a multi-span continuous beam with cracks. Applied Mechanics and Materials, 256, (2013), pp. 964-972. doi:10.4028/www.scientific.net/AMM.256-259.964.

[12] T. V. Lien and T. A. Hao. Determination of mode shapes of a multiple cracked beam element and its application for free vibration analysis of a multi-span continuous beam. Vietnam Journal of Mechanics, 35, (4), (2013), pp. 313-323. doi:10.15625/0866-7136/35/4/2520.

[13] D. S. Sharma, M. J. Mungla, and K. H. Barad. Vibration-based non-destructive technique to detect crack in multi-span beam. Nondestructive Testing and Evaluation, 30, (4), (2015), pp. 291311. doi:10.1080/10589759.2015.1029475.

[14] M. J. Mungla, D. S. Sharma, and R. R. Trivedi. Inverse method to identify crack parameters in multi-span beam using genetic algorithm. Nondestructive Testing and Evaluation, 32, (3), (2017), pp. 301-318. doi:10.1080/10589759.2016.1226302.

[15] G. Tan, Z. Zhu, W. Wang, and Y. Cheng. Free vibration analysis of a uniform continuous beam with an arbitrary number of cracks and spring-mass systems. Arabian Journal for Science and Engineering, (2017), pp. 1-16. doi:10.1007/s13369-017-2933-0. 
[16] N. T. Khiem and H. T. Tran. A procedure for multiple crack identification in beam-like structures from natural vibration mode. Journal of Vibration and Control, 20, (9), (2014), pp. 14171427. doi:10.1177/1077546312470478.

[17] S. Caddemi and I. Calio. Exact closed-form solution for the vibration modes of the EulerBernoulli beam with multiple open cracks. Journal of Sound and Vibration, 327, (3-5), (2009), pp. 473-489. doi:10.1016/j.jsv.2009.07.008.

[18] T. G. Chondros, A. D. Dimarogonas, and J. Yao. A continuous cracked beam vibration theory. Journal of Sound and Vibration, 215, (1), (1998), pp. 17-34. doi:10.1006/jsvi.1998.1640. 